\title{
Technical note: A method for isolating glycogen granules from ruminal protozoa for further characterization ${ }^{1}$
}

\author{
Mary Beth Hall ${ }^{2}$ \\ US Dairy Forage Research Center, USDA-Agricultural Research Service, Madison, WI 53706
}

\begin{abstract}
Evaluation of physical, chemical, and enzymatic hydrolysis characteristics of protozoal glycogen is best performed on a pure substrate to avoid interference from other cell components. A method for isolating protozoal glycogen granules without use of detergents or other potentially contaminating chemicals was developed. Rumen inoculum was incubated anerobically in vitro with glucose. Glycogen-laden protozoa produced in the fermentation, primarily isotrichids, were allowed to sediment in a separatory funnel and were dispensed. The protozoa were processed through repeated centrifugations and sonication to isolate glycogen granules largely free of feed and cellular debris. The final water-insoluble lyophilized product analyzed as 98.3\% $\alpha$-glucan with very rare starch granules and $1.9 \%$ protein. Observed losses of glycogen granules during the clean-up process indicate that this procedure should not be used for quantitative assessment of protozoal glycogen from fermentations. Further optimization of this procedure to enhance the amount of glycogen obtained per fermentation may be possible.
\end{abstract}

Key words: rumen, glycogen, protozoa

\section{Technical Note}

Protozoal glycogen is an intracellular storage polysaccharide composed of $\alpha$-1,4-linked D-glucose with a-1,6-linked branches (Forsyth and Hirst, 1953). The presence of glycogen in ruminal protozoa was first reported by Certes (1889), and it has been reported to be stored in granules and in skeletal plates (Jouany and Ushida, 1999). Glycogen is produced from a variety of soluble (glucose, fructose, sucrose, fructan) and insoluble (starch) carbohydrates (Oxford, 1951).

\footnotetext{
Received September 7, 2015.

Accepted November 16, 2015.

${ }^{1}$ Mention of any trademark or proprietary product in this paper does not constitute a guarantee or warranty of the product by the USDA or the Agricultural Research Service and does not imply its approval to the exclusion of other products that also may be suitable.

${ }^{2}$ Corresponding author: marybeth.hall@ars.usda.gov
}

Isotrichid protozoa in the rumen can produce substantial amounts of glycogen, storing it internally as small (1-2 $\mu \mathrm{m}$ diameter) water-insoluble granules (Oxford, 1951). Glycogen-laden isotrichid protozoa sediment easily, allowing their separation from other components of a fermentation culture, and isolation of the glycogen granules (Oxford, 1951). To evaluate the physical, chemical, and enzymatic hydrolysis characteristics of protozoal glycogen granules, they need be isolated in relatively pure form to avoid interference from other cellular components. One approach to isolation used detergent to lyse the protozoa and release the glycogen granules, which were then collected by centrifugation (Oxford, 1951). However, the insolubility of the granules in water and their sedimentation characteristics alone allowed development of the following method for isolating glycogen granules primarily from isotrichid protozoa without the potential contamination of detergents. The glucose substrate used favors glycogen accumulation by isotrichids rather than entodiniomorphid protozoa because of the slow metabolism of glucose by the latter (Oxford, 1959). Further optimization of the procedure to provide more glycogen per fermentation may be possible and may be specific to the animals and diets used, but was beyond the scope of the present experiment. Factors that may bear evaluation include concentration of glucose or other sugar used, method of straining the rumen fluid to include maximal numbers of protozoa in the inoculum (Dehority, 1984), profile of the ruminal protozoa population present, and diets provided to the inoculum donors.

For the in vitro fermentation procedure, cultures of mixed ruminal microbes were grown anaerobically with glucose to produce protozoa for isolation of protozoal glycogen granules. Mixed ruminal inoculum was obtained from 2 ruminally cannulated, lactating Holstein cows maintained under protocols approved by the University of Wisconsin Animal Care and Use Committee. Donor cows were fed a TMR once daily at $0700 \mathrm{~h}$. The diet consisted on a DM basis of $312 \mathrm{~g} / \mathrm{kg}$ of corn silage, $224 \mathrm{~g} / \mathrm{kg}$ of alfalfa silage, $63 \mathrm{~g} / \mathrm{kg}$ of whole linted cottonseed, $4 \mathrm{~g} / \mathrm{kg}$ of dextrose, and $395 \mathrm{~g} / \mathrm{kg}$ of mixed, corn grain-based concentrate supplemented with vitamins and minerals to meet NRC (2001) rec- 
ommendations. Rumen fluid obtained $2 \mathrm{~h}$ postfeeding was transferred manually from the rumen to warmed, insulated containers. In the laboratory, approximately $800 \mathrm{~mL}$ of the rumen fluid for each cow was strained through 4 layers of cheesecloth into a graduated cylinder with $\mathrm{CO}_{2}$ continuously bubbled through the fluid. The rumen fluid from each animal was swirled vigorously to mix, and $500 \mathrm{~mL}$ from each animal was measured into graduated cylinders and filtered through 4 layers of cheesecloth into a common 2-L Erlenmeyer flask. Carbon dioxide was bubbled continuously through the combined rumen fluid, and the flask was maintained at $39^{\circ} \mathrm{C}$ until inoculation.

A modified Goering and Van Soest (1970) medium was prepared which omitted casein hydrolysate (normally included at $2.5 \mathrm{~g} / \mathrm{L}$ of medium). The medium consisted of $500 \mathrm{~mL}$ of distilled water, $250 \mathrm{~mL}$ of buffer (72.0 g of $\mathrm{NH}_{4} \mathrm{HCO}_{3}, 630 \mathrm{~g}$ of $\mathrm{NaHCO}_{3}, 18 \mathrm{~L}$ of distilled water), $250 \mathrm{~mL}$ of macromineral solution (102.6 g of $\mathrm{Na}_{2} \mathrm{HPO}_{4}, 111.6 \mathrm{~g}$ of $\mathrm{KH}_{2} \mathrm{PO}_{4}, 10.5 \mathrm{~g}$ of $\mathrm{MgSO}_{4} \cdot 7 \mathrm{H}_{2} \mathrm{O}$, $18 \mathrm{~L}$ of distilled water), $0.125 \mathrm{~mL}$ of micromineral solution $\left(13.2 \mathrm{~g}\right.$ of $\mathrm{CaCl}_{2} \cdot 2 \mathrm{H}_{2} \mathrm{O}, 10 \mathrm{~g}$ of $\mathrm{MnCl}_{2} \cdot 4 \mathrm{H}_{2} \mathrm{O}, 1 \mathrm{~g}$ of $\mathrm{CoCl}_{2} \cdot 6 \mathrm{H}_{2} \mathrm{O}, 8 \mathrm{~g}$ of $\mathrm{FeCl}_{3} \cdot 6 \mathrm{H}_{2} \mathrm{O}$ brought to $100-\mathrm{mL}$ volume with distilled water), and $1.25 \mathrm{~mL}$ of $0.1 \%$ (wt/ vol) resazurin solution. The medium was prepared the day before fermentation. Carbon dioxide was bubbled through it for $1 \mathrm{~h}$ via a diffusing stone, the flask was stoppered, and stored overnight at $4^{\circ} \mathrm{C}$. The day of the fermentation, $400 \mathrm{~mL}$ of medium was measured into each 1-L Erlenmeyer flask. The headspaces were gassed with $\mathrm{CO}_{2}$, the flasks stoppered, and incubated at $39^{\circ} \mathrm{C}$ in a water bath or in an appropriately heated incubation room. Reducing solution $(20 \mathrm{~mL}$; $95 \mathrm{~mL}$ of distilled water, $0.625 \mathrm{~g}$ of cysteine $\mathrm{HCl}, 4 \mathrm{~mL}$ of $1 \mathrm{~N} \mathrm{NaOH}$, and $0.625 \mathrm{~g}$ of $\mathrm{Na}_{2} \mathrm{~S} \cdot 9 \mathrm{H}_{2} \mathrm{O}$ ) was added to each flask. Resazurin-mediated color change from blue or pink (not reduced) to a light yellow/no color (reduced) was used to verify anaerobicity of the medium. Glucose (1.5 g) was added to each flask and swirled to completely solubilize it. The flask of prepared rumen inoculum was swirled to mix and $100 \mathrm{~mL}$ was added to the medium in each flask. Inoculated flasks were swirled, head space gassed with $\mathrm{CO}_{2}$, stoppered, and incubated at $39^{\circ} \mathrm{C}$ for $2 \mathrm{~h}$. Flasks were swirled every $15 \mathrm{~min}$ during incubation.

After $2 \mathrm{~h}$, the fermentation flasks were swirled to suspend all particulate matter, and contents of each flask were transferred with sparing rinsing with $0.9 \%$ $\mathrm{NaCl}$ to a 1-L separatory funnel. The fermentation cultures were allowed to sediment for approximately 40 min. A distinct layer of white material (microscopically identified as isotrichid protozoa) settled to the bottoms of the funnels. The white material from each funnel was carefully dispensed into a $15-\mathrm{mL}$ conical tube with effort to minimize contamination with feed particles above the white protozoal layer. Conical tube contents were suspended with $0.9 \%$ saline to a total volume of 10 to $15 \mathrm{~mL}$ and centrifuged at $1,000 \times g$ for $10 \mathrm{~min}$ at $5^{\circ} \mathrm{C}$. The supernatant was aspirated off, the pellet resuspended in $0.9 \%$ saline and centrifuged at $1,000 \times$ $g$ for $10 \mathrm{~min}$ at $4^{\circ} \mathrm{C}$. The supernatant was aspirated off, and the pellet resuspended with $0.9 \%$ saline to a total volume of approximately $5 \mathrm{~mL}$. The supernatant after each centrifugation was still slightly cloudy, containing cellular debris as well as some free glycogen granules; these were removed with the supernatant.

The sample was then sonicated (Ultrasonic Processor \#S-4000, Misonix Inc., Farmingdale, NY) at an amplitude setting of 10 for a total of $49 \mathrm{~s}$ in bursts of 5 s. The total energy input from sonication was 574 J. Samples were put on ice to cool between bursts if the sample became warm to the touch. Samples became frothy, opaque, and bright white in appearance. Microscopic examination of sonicated samples revealed no intact protozoa, but much fine debris and intact glycogen granules.

Samples were brought to approximately 10 to $12 \mathrm{~mL}$ with $0.9 \%$ saline and centrifuged at $5,000 \times g$ for 10 min at $5^{\circ} \mathrm{C}$. Both the supernatant and a greenish, slimy layer of cellular debris on top of the solid white pellet were aspirated off. An inoculating loop was then used to scrape off and remove obvious portions of the greenish layer that formed a layer over the white pellet. The pellet was resuspended with vortexing in $0.9 \%$ saline, centrifuged, aspirated, and slime layer removed with a loop. During this process, some glycogen may be lost as the cellular debris is scraped off.

The pellet was then suspended in $18-\mathrm{M} \Omega$ purified water and centrifuged at $5,000 \times g$ for $10 \mathrm{~min}$ at $5^{\circ} \mathrm{C}$. As with the previous centrifugations, both the supernatant and a greenish layer of cellular debris on top of a solid white pellet were aspirated off. An inoculating loop was used to scrape off and remove obvious portions of the greenish layer. The pellet was resuspended in purified water and the centrifugation, aspiration, and removal of slime layer was repeated. With each successive centrifugation, the amount of fine, suspended material in the supernatant and greenish material decreased. After each centrifugation, the pellet was examined for presence of the layer of greenish cellular debris, and the supernatant was examined microscopically for evidence of nonglycogen cellular debris. When such debris was no longer noted, purification of the glycogen was deemed complete. Photos of materials in the separatory funnels and micrographs of glycogen-laden protozoa, nonglycogen cellular debris, and isolated glycogen granules are in Supplemental Figures S1 through S7 (http://dx.doi. org/10.3168/jds.2015-10357). 
Samples then were suspended with vortexing in approximately $3 \mathrm{~mL}$ of purified water, frozen, and freeze dried. Yield of protozoal glycogen was 0.12 to $0.16 \mathrm{~g}$ per fermentation flask, or 8 to $11 \%$ of the glucose substrate. This is comparable to the reported 5 to $10 \%$ of total sugars converted to "protozoan starch" in vitro in fermentations with mixed ruminal inoculum and $0.5 \%$ glucose (Masson and Oxford, 1951). The yield of protozoal glycogen is somewhat less than the maximum detected $15 \%$ of glucose substrate measured as total bacterial and protozoal glycogen in fermentations with mixed ruminal microbes (Hall and Weimer, 2016). However, if protozoa account for approximately $50 \%$ of the total detected microbial glycogen in fermentations with glucose (Hall, 2011), the recoveries of present and past studies do appear to be comparable.

The isolated lyophilized glycogen was analyzed as $97.9 \% \mathrm{DM}$ (determined at $105^{\circ} \mathrm{C}$ ). Duplicate analyses of the glycogen gave, on a DM basis, $98.3 \%(\mathrm{SD}=0.01 \%)$ $\alpha$-glucan as determined with a starch assay (AOAC Official Method 2014.10 in Hall, 2015), and 1.9\% protein $(\mathrm{SD}=0.2 \%)$ as determined with the Bradford assay (\#1856210, Bio-Rad Coomassie-Plus reagent, Thermo Scientific, Rockford, IL; lysozyme used as the standard) applied after boiling samples in $0.2 M \mathrm{NaOH}$ for 15 min, and centrifuging for $12,000 \times g$ for $10 \mathrm{~min}$ at $5^{\circ} \mathrm{C}$. For comparison, beef liver glycogen (type IX; G0885, Sigma Aldrich, St. Louis, MO) and wheat starch (S5127, Sigma, St. Louis, MO) analyzed in the same starch analytical run gave $\alpha$-glucan values (mean \pm SD) of $98.1 \pm 0.07 \%$ and $99.5 \pm 0.57 \%$, respectively, as a percentage of DM.

Microscopic evaluation of the protozoal glycogen granule preparation under polarized light showed very rare starch granules present; starch granules exhibited obvious birefringence and glycogen granules did not. It is suspected that the source of the starch granules was starch from the donor cow diet that had been ingested by the sedimented isotrichid protozoa (Sugden and Oxford, 1952). The 1- to 2- $\mu$ m-diameter ovoid glycogen granules had the same appearance as those released by lysis of isotrichid protozoa as observed with light microscopy.

Purity of the isolates can be assessed with microscopic evaluation of aqueous suspensions of granules for presence or absence of cellular debris or nongranule material, as well as $\alpha$-glucan analysis of $>97 \%$ of sample DM. Analyses of $100 \% \alpha$-glucan may not be attainable because glycogen granules may contain pro- tein molecules, phosphate esters, and monosaccharide residues other than D-glucose (Manners, 1991). Observed losses of glycogen granules during the isolation process indicate that this procedure should not be used for quantitative assessment of protozoal glycogen from fermentations.

\section{ACKNOWLEDGMENTS}

Special thanks go to the staff at the University of Wisconsin Laboratory for Optical and Computational Instrumentation for assistance with polarized light microscopy, and to J. W. Pitas and P. J. Weimer, US Dairy Forage Research Center, USDA-ARS, Madison, Wisconsin, for analytical assistance. This research was supported by funding from USDA, Agricultural Research Service under National Program 101 Food Animal Production.

\section{REFERENCES}

Certes, A. 1889. Note sur les micro-organismes de la panse des ruminants. Bull. Soc. Zool. Fr. 14:70-73.

Dehority, B. A. 1984. Evaluation of subsampling and fixation procedures used for counting rumen protozoa. Appl. Environ. Microbiol. 48:182-185.

Forsyth, G., and E. L. Hirst. 1953. Protozoal polysaccharides. Structure of the polysaccharide produced by the holotrich ciliates present in sheep's rumen. J. Chem. Soc. 2132-2135.

Goering, H. K., and P. J. Van Soest. 1970. Forage fiber analysis (apparatus, reagents, procedures and some applications). Agriculture handbook no. 379. ARS-USDA, Washington, DC.

Hall, M. B. 2011. Isotrichid protozoa influence conversion of glucose to glycogen and other microbial products. J. Dairy Sci. 94:4589-4602.

Hall, M. B. 2015. Determination of dietary starch in animal feeds and pet food by an enzymatic-colorimetric method: Collaborative study. J. AOAC Int. 98:397-409.

Hall, M. B., and P. J. Weimer. 2016. Divergent utilization patterns of grass fructan, inulin, and other nonfiber carbohydrates by ruminal microbes. J. Dairy Sci. 99:245-257. http://dx.doi.org/10.3168/ jds.2015-10417.

Jouany, J. P., and K. Ushida. 1999. The role of protozoa in feed digestion: Review. Asian-austral. J. Anim. Sci. 12:113-128.

Manners, D. J. 1991. Recent developments in our understanding of glycogen structure. Carbohydr. Polym. 16:37-82.

Masson, F. M., and A. E. Oxford. 1951. The action of the ciliates of the sheep's rumen upon various water-soluble carbohydrates, including polysaccharides. J. Gen. Microbiol. 5:664-672.

NRC. 2001. Nutrient Requirements of Dairy Cattle. 7th rev. ed. National Academy Press, Washington, DC.

Oxford, A. E. 1951. The conversion of certain soluble sugars to a glucosan by holotrich ciliates in the rumen of sheep. J. Gen. Microbiol. 5:83-90.

Oxford, A. E. 1959. Bloat in cattle. N. Z. J. Agric. Res. 2:365-374.

Sugden, B., and A. E. Oxford. 1952. Cultural studies with holotrich ciliate protozoa of the sheep's rumen. J. Gen. Microbiol. 7:145-153. 